\author{
KRYSTYNA MISIUNA \\ University of Warsaw \\ Department of Logic \\ krystyna.simons@uw.edu.pl
}

\title{
HOW TO DEFINE THE NOTION OF KNOWLEDGE WHICH SOLVES THE GETTIER PROBLEM
}

\begin{abstract}
Our contention is that to solve the Gettier Problem, a notion of infallible knowledge involving the substantial truth theory is necessary. We assume that acts of sense experience have propositional content, and that atomic empirical propositions need the existence of non-mental objects to be true. This approach allows for making the distinction between epistemically good justifiers and ontologically good justifiers, and leads to a definition of propositional empirical knowledge free of the Gettier Problem. Our explication of the Gettier Problem rejects Hetherington's (2012) view that the Gettier Problem rests on jointly unsatisfiable constraints, sheds a new light on Floridi's (2004) result, avoids the Pyrrhonian skepticism, as well as the skepticism defended by Kirkham (1984), and vindicates the substantial notion of truth.
\end{abstract}

Keywords. Evidence, truth, knowledge, fallibilism, infallibilism, Gettier Problem.

\section{What is the Gettier Problem?}

Gettier ([1963]) poses the question: What do we mean when we say that someone knows something, for example, that Smith knows that Jones owns a Ford? Although the Gettier type counterexamples have been familiar since the time Gettier's paper was published, the Gettier Problem is not recognized in the same way by those who deal with it. Kirkham ([1984]) defines the Gettier Problem as a problem which rests on a mistaken assumption. This mistaken assumption consists in the attempt to find such an explication of knowledge which

(i) includes all or most of the beliefs we commonly regard as knowledge, and

(ii) excludes any belief which the subject does not know on that explication, that is, is immune to all Gettier type counterexamples.

Kirkham concludes that there is no explication which fulfills both conditions (i) and (ii). He argues that to get the weakest explication of "a knows that p", which is immune to all Gettier type counterexamples, we must accept the following explication of knowledge: (1) p is true; (2) the subject believes that p; 
and (3) justification needed for knowledge must begin from self-evident for the subject premises, and these premises must necessitate the truth of proposition $\mathrm{p}$. Satisfying these conditions we fail to give such an explication of knowledge which includes all (or most) beliefs regarded as knowledge. Since, as Kirkham argues, there cannot be another explication which could be immune to all Gettier type counterexamples, there is no explication at all which meets parts (i) and (ii) of the mistaken assumption. The general conclusion of Kirkham's analysis of knowledge is that most of our ordinary knowledge attributions are incorrect. Kirkham includes in our knowledge only a few propositions, besides necessary truths, such as: "I believe something", "I think my name is Smith" (not "my name is Smith"), "I am in pain", "Somebody believes something" (deduced from "I believe something").

We do not define the Gettier Problem by the two-part condition formulated by Kirkham. Part (i) of Kirkham's condition is true when it is interpreted as a certain tendency existing at a certain period of time in a philosophical community. We agree that a comprehensive solution of the Gettier Problem should take into account most beliefs we commonly regard as knowledge. However, some restrictions are necessary, since any adequate definition of "a knows X", where X stands for an arbitrary belief regarded by "a" as an instance of knowledge, ceteris paribus is impossible. A definition of this kind should be formulated for a fragment of natural language. From our point of view, also part (ii) of Kirkham's condition should be modified, and should be understood in the following way. Any adequate definition of "a knows $X$ " for a given fragment of natural language is immune to those Gettier type counterexamples which could be formulated exclusively for that fragment of natural language for which a given definition has been formulated. We are aiming at giving a definition of this kind in the present paper.

Kirkham gives us the following explication of self-evident proposition: $\mathrm{p}$ is selfevident for the subject if and only if (i) if the subject believes $p$, then $p$ is true, and (ii) $\mathrm{p}$ cannot fail to be true whenever the subject believes $\mathrm{p}$ as subject's rational reason to believe $\mathrm{p}^{2}$ Kirkham's explication of self-evidence allows for different interpretations, because the concept of evidence, as well as that of rationality have many different senses depending on the philosophical context. Since we cannot formulate any adequate definition of knowledge without the concept of evidence, we need to have at our disposal a satisfactory explication of the evidence.

\footnotetext{
${ }^{1}$ KIRKHAM [1984], p. 502.

${ }^{2}$ Ibid.
} 


\title{
2. What is Evidence?
}

The word "evidence" in one of its meanings means the ground for knowledge. ${ }^{3}$ The problem connected with this meaning of evidence, which is relevant to our further argument, is formulated explicitly in Davidson (1983). Davidson wrote:

\begin{abstract}
The relation between a sensation and a belief cannot be logical, since sensations are not beliefs or other propositional attitudes. What then is the relation? The answer is, I think, obvious: the relation is causal. Sensations cause some beliefs and in this sense are the basis or ground of those beliefs. But a causal explanation of a belief does not show how or why the belief is justified (DAVIDSON [2006], p. 229).
\end{abstract}

The answer to our problem must then be to find a reason for supposing most of our beliefs are true that is not a form of evidence (DAVIDSON [2006], p. 232).

This view implies that sense experiences do not have propositional content, and if a mental state is to play the role of a justifier, it necessarily has propositional content. In consequence, on this view, sense experiences cannot play the role of justifiers, and Davidson's argument contradicts the foundationalist account of justification which rests on the following thesis.

(F) Sense experience is a source of non-inferential justification.

The foundationalist may respond in two different ways to Davidson's argument.

(1) He (or she) may accept the claim that sense experience does not have propositional content, and may reject the claim that having propositional content by mental states is necessary for justification;

(2) He (or she) may accept the claim that having propositional content by mental states is necessary for justification, and may reject the claim that sense experience does not have propositional content.

The rejection of Davidson's claim that sense experiences are devoid of propositional content is supported by the theory of intentionality which states that mental acts, including acts of perception, like acts of seeing, hearing or smelling, as well as mental acts of loving, hating, desiring, believing, judging,

\footnotetext{
${ }^{3}$ This meaning, besides two others, is explicitly specified in FENNELL, CARTWRIGHT [2010]), p. 291. I shall concentrate on this meaning, although the other meanings (leveraging and relevance) are also widely discussed by contemporary epistemologists. Cf. ROUSH [2005]. I should like also to mention WILLIAMSON's [2000] concept of evidence identified with knowledge.
} 
hoping, and many others are intentional acts, directed at their objects. ${ }^{4} \mathrm{We}$ should note that the property of being directed at something is independent of the physical existence of the object towards which the mind is directed. In this respect, states of knowledge and belief states differ, and only beliefs, not states of knowledge, can be directed towards non-existent entities. One may say that unlike belief reports, reports of knowledge are veridical. It is not only Davidson who may be regarded as a critic of foundationalism. First of all, we must mention Wilfrid Sellars who in his famous (1956) paper aims at giving an answer to the question how sense-experiences play the role of justifiers. An accurate account of his position may be found in Matthias Steup's ([2001b]) paper which calls the problem the Sellarsian Dilemma. The foundationalist is faced with a choice; the sense-experiential state is either a belief, or it is not. If it is a belief, the question arises what could turn a sense-experiential state into a belief. It must be the possession of propositional content. If a senseexperiential state has propositional content, then such a state must be another belief which needs its own justification, and this way, we obtain the justificatory regress. On the other hand, if one assumes that sense-experiential states do not have propositional content, then they cannot be justifiers of any basic belief. Now, if we accept the position that sense-experiential states have propositional content, we need to argue that the presence of propositional content does not turn sense-experiential states into beliefs, since sense-experiential states, even with propositional content, are not something that can be justified. How can we argue that the presence of propositional content does not turn sense-experiential states into beliefs? Each sense-experiential state, if it has propositional content, is an intentional state directed at its object, that is, the proposition which has the same content. Note that not all intentional states possess epistemic justification; for example, hopes, fears and desires are intentional states of this kind. Having propositional content is insufficient to be epistemically justified. Matthias Steup gives the following argument for the claim that sense-experiential states have propositional content, but do not require justification.

Suppose you ask me: What justifies you in believing that your coffee is sweet? This is a sensible question, and it has a sensible answer. The answer would be: "It tastes sweet." But now suppose we were to ask: "But what justifies you in experiencing the coffee as tasting sweet, i.e. in having a sense experience that has as its content the proposition that the coffee is sweet?" Well, this is not a sensible question. If you were to ask me that kind of a question, I would have to reply that I don't know what you mean. Now, what this consideration suggest is this: the sort of mental states that are epistemically justified or unjustified are not sense experiences, but rather the doxastic attitudes we form in responses to sense experiences. So I conclude once again that sense experiences with propositional

\footnotetext{
${ }^{4}$ This idea was considered by M. Steup in STEUP [2001b].
} 
content do not admit epistemic justification, and thus can justify without being justified themselves (STEUP, [2001b], p. 5).

We regard Steup's way of replying to the Sellarsian Dilemma as convincing and conforming to our view concerning sensory contents. We shall be using the concept of sense experience in the intentional meaning outlined above. On this view, sense experiences may be regarded as legitimate justifiers. ${ }^{5}$

Let $\mathrm{L}$ be a simple language of evidence consisting of (1) symbols for $\mathrm{n}$-ary predicates, for an arbitrary $\mathrm{n} \in \mathrm{N}$, representing natural language predicates and relations; (2) symbols for individual constants representing proper names, demonstratives and other individual terms of natural language: a, c, e (with subscripts, if necessary); (3) symbols for sentential truth-functional connectives representing natural language connectives such as "either...or" "and" and others if necessary; (4) symbols for time intervals: $t$, $t$ ' ordered by the relation $\geq$. Sentences formed by a predicate and individual term(s) are denoted as $\mathrm{p}, \mathrm{q}, \ldots$, and a proposition that $\mathrm{p}$ is denoted as $\langle\mathrm{p}>$. The proposition that $p$ holds at $t$ is denoted as $\langle\mathrm{p} / \mathrm{t}\rangle$. Compound sentences built with the help of truth-functional connectives will be denoted as P, Q; the symbol E! stands for "exists".

Definition 1 If "c" is an act of sense experience (act of perception) directed at $<\mathrm{p}>$ at time $\mathrm{t}$, then $<\mathrm{p}>$ is an epistemically good justifier of $<\mathrm{q}>$ in $\mathrm{L}$ if and only if person "a" believes $<\mathrm{q} / \mathrm{t}>$ is true. In other words, person a's belief in $<\mathrm{q}>$ at $\mathrm{t}$ is a consequence of the occurrence of the sense experience directed at $<p>$ at time t.

Example 1. Anticipating Gettier's examples, one may say that Smith has the visual experience at time $\mathrm{t}<$ Jones drives a Ford $>$ which is an epistemically good justifier for the proposition $<$ Jones owns a Ford $>$ if and only if Smith believes that $<$ Jones owns a Ford at $t>$ is true.

Suppose that Smith has the visual experience $<$ This cube is red $>$ when looking at an previously unknown cube painted white in a room where there is a red light-bulb in the room's light-socket at a certain time interval $t$. Then $<$ This cube is red $>$ is an epistemically good justifier of the proposition $<$ This cube is red $>$ in $\mathrm{L}$ if and only if Smith believes that $<$ This cube is red at $\mathrm{t}>$ is true. But Smith may know that the light in the room is red, and may formulate the content of his visual experience as $<$ This cube looks red $>$, or as $<$ In this light, this cube looks red $>$. Then his sense experiences individually are epistemically good justifiers of the proposition $<$ This cube looks red $>$ in L if and only if Smith believes $<$ This cube looks red at $\mathrm{t}>$. Definition 1 does not exclude that all Smith's sense

\footnotetext{
${ }^{5}$ I shall not discuss here the problem of epistemic circularity connected with the thesis (F). A nice account of this problem may be found in BERGMAN [2004].
} 
experiences listed above are individually epistemically good justifiers of the proposition $<$ This cube is white $>$ or $<$ This cube is green $>$, or even of another proposition. To exclude arbitrary epistemically good justifiers, Definition 1 needs a proper understanding of the subject of beliefs.

Presupposition: We assume that the subject of beliefs is a self-conscious and competent speaker of his (her) native language, normally mentally developed, having statistically normal color vision at the time of his (her) visual experience, and is of a normal and undisturbed state of mind.

Let us consider episodic mental acts such as hearings in the role of epistemically good justifiers. Suppose that Mary has a baby whose name is Rupert, and that at a certain time interval $t$ she hears $<$ Rupert is howling $>$. Her act of sense experience at $t$ is an epistemically good justifier of the proposition $<$ Rupert needs something $>$ if and only if Mary believes $<$ Rupert needs something at $t>$ is true.

How could we include testimony to epistemically good justifiers? Suppose Smith has been told by the president of a company that Jones is not well educated to get a higher post. Thus, Smith has at $t$ the testimony $<$ Jones is not well educated to get a higher post $>$ which is an epistemically good justifier of $<$ Jones is not well educated to get a higher post $>$ if and only if Smith believes $<$ Jones is not well educated to get a higher post at $t>$ is true. Let us take another example. ${ }^{6}$ Suppose that Smith has been told by his cousin Ernie that the moon is made of green cheese, and Smith has at $t$ the testimony $<$ The moon is made of green cheese $>$ which is an epistemologically good justifier of $<$ The moon is made of green cheese $>$ if and only if Smith believes that $<$ The moon is made of green cheese $>$ is true. We shall return to similar examples below.

These examples appeal silently to some important ontological distinctions. They involve individual objects like instances of colors and instances of events which in contemporary ontology are most frequently called tropes, and they involve ontological relation of ontological dependence. A trope is an object whose existence is ontologically dependent upon the existence of another object. How should this dependence be understood? The relation of ontological dependence is an essential property of a trope, and any account of this relation must appeal to the notion of ontological necessity, that is, de re necessity, understood as a consequence of the necessary structure of objects and their configurations. Those objects on which a trope depends are called its fundaments. Now, if an object has a part which is essential it is in one sense necessarily dependent on that part. But the fundaments of a trope cannot be wholly contained within it as its proper or improper parts. This requirement also excludes the case that

\footnotetext{
${ }^{6}$ This example has been borrowed from KIRKHAM [1984], p. 504.
} 
everything is its own fundament, and, in consequence, that everything is its own trope. Thus, tropes may be defined in the following way: $\mathrm{T}$ is a trope if and only if $\mathrm{T}$ exists and $\mathrm{T}$ is ontologically necessarily such that either $\mathrm{T}$ does not exist, or there exists at least one object $\mathrm{O}$, which is ontologically possibly such that it does not exist, and which is not a proper or improper part of $\mathrm{T}^{7}$ Objects which are not tropes are called independent objects or substances. Note that the relation of foundation may bind together individual objects, for example, an individual location and a trope, say, an instance of a particular color. These two individual objects are linked by the relation of mutual foundation. To give another example, two atoms such that atom A strikes at time $t$ atom B are linked by two relations of foundation which hold between the particular event of striking, $\mathrm{C}$, and $\mathrm{A}$, and between $\mathrm{C}$ and $\mathrm{B}$.

\section{Explanatory Role of Truth}

Although Davidson did not consider himself to be a deflationist, he held the view that truth is transparent. ${ }^{8}$ His view is close to the declaration upheld by deflationists who claim that the truth predicate is without any substantial content and without any substantial explanatory role, with its sole role being a "syntactic device". Such a conception of truth will not be applied in the present paper. We need a substantial theory of truth whose main idea is expressed by the following assumption.

Assumption: The sufficient and necessary conditions of truth of atomic propositions is the existence of entities non-reducible to our mental states.

Example 2. Let "this speck" refers to location $\mathrm{e}_{1}$. Then the truth conditions of the proposition $<$ This speck is red at $\mathrm{t}>$ should be formulated in the following way:

$<$ This speck is red at $\mathrm{t}>$ is true if and only if the location, $\mathrm{e}_{1}$, and the individual property of redness, $\mathrm{e}_{2}$, exist at $\mathrm{t}$ and are linked at $\mathrm{t}$ by the ontological relation of mutual dependence. ${ }^{9}$

These truth-conditions make use of the ontology accepting the existence of two kinds of entities: independent and dependent. An individual property, being

\footnotetext{
${ }^{7}$ Cf. MULLIGAN, SIMONS, SMITH [1984], p. 294.

${ }^{8}$ DAVIDSON [2006], pp. 226-227.

9 Cf. MULligAN, SIMONS, SMITH [1984], p. 310. The entity e which is ontologically independent of the entity e' may be ontologically dependent on the entity e'". The meaning of $e$ being ontologically dependent on $e^{\prime}$ has been given below.
} 
a trope, is an entity whose existence is essentially dependent upon that of another entity. ${ }^{10}$ We may define the relation of ontological dependence (OD) in the language of the first order modal logic in the following way. ${ }^{11}$

(OD) e is ontologically dependent on $\mathrm{e}^{\prime}:=\square\left[\exists \mathrm{x}(\mathrm{x}=\mathrm{e}) \rightarrow \exists \mathrm{y}\left(\mathrm{y}=\mathrm{e}^{\prime}\right)\right]$.

Individual properties and individual events are regarded as examples of essentially dependent entities, whereas substances are regarded as independent entities. ${ }^{12}$ We have to do with the ontological relation of mutual dependence of two dependent entities in Example 2: the location $\mathrm{e}_{1}$ and the individual property (trope) of redness, $\mathrm{e}_{2}$. This means that the existence of the location $\mathrm{e}_{1}$ is ontologically necessary for the existence of the individual property of redness, $\mathrm{e}_{2}$, and vice versa: the existence of the individual property of redness, $\mathrm{e}_{2}$, is ontologically necessary for the existence of location $\mathrm{e}_{1}$.

Our reasons for accepting the existence of independent and dependent entities are partly epistemological, because our aim is to formulate an adequate definition of knowledge for propositions formulated in natural language which is modeled by our language of evidence L. Hence, our ontology accepts the existence of those entities which are recognized by the users of natural language without making use of any advanced language of science, like the language of the special relativity theory, or the language of a theory of elementary particles, or quantum mechanics, or another language of a scientific theory.

What can we accept as evidence of beliefs if we assume, according to our Assumption, that the truth conditions of atomic propositions is the existence of entities different from our mental states? Founationalists claim that our sense experiences are evidence of our true beliefs. Does it mean that epistemically good justifiers defined by Definition 1 can play the role of sufficient and necessary condition of truth? No. Sense experiences which are epistemically good justifiers cannot play the role of sufficient and necessary conditions of truth on the ground of our Assumption. We need ontologically good justifiers of $<\mathrm{p}>$ as sufficient and necessary conditions of the truth of $<\mathrm{p} / \mathrm{t}>$.

\footnotetext{
${ }^{10}$ Individual properties as dependent entities are called moments in MULLIGAN, SIMONS, SMITH [1984]. At present, the widely accepted name for dependent entities is "tropes". Cf. CAMPBELL [1990], SIMONS [1994], [2000], BACON [1995], MCDANIEL [2001], TRETTIN [2001], MAURIN [2002], [2010], HEIL [2003], to mention only a few philosophers arguing for the ontology of tropes.

${ }^{11}$ On the concept of ontological dependence cf. MULLIGAN, SIMONS, SMITH [1984], p. 294, and CAMERON [2008], pp. 37-38.

12 An argument for accepting the ontology of substances and tropes has been convincingly formulated by R. P. Cameron in CAMERON [2008].
} 
Definition 2 Entities $\mathrm{e}_{1}, \ldots, \mathrm{e}_{\mathrm{n}}$ are ontologically good justifiers of the proposition $<\mathrm{p}>$ in $\mathrm{L}$ if and only if the joint existence of $\mathrm{e}_{1}, \ldots, \mathrm{e}_{\mathrm{n}}$ at $\mathrm{t}$ is the sufficient and necessary condition of the truth of $\langle\mathrm{p} / \mathrm{t}\rangle$.

If this cube is white at $\mathrm{t}$, then the joint existence of this cube and the individual property of whiteness is the sufficient and necessary condition of the truth of $<$ This cube is white at $t>$. The proposition $<$ This cube is red at $t>$ where "this cube" designates this cube is false, but false propositions do not have ontologically good justifiers. The proposition $<$ This cube looks red at t'> is true and has its ontologically good justifiers: this cube, and the individual event existing at t' Smith of looking at this cube in the red light.

In Example 2, the joint existence of the location $\mathrm{e}_{1}$ and the individual property of redness $\mathrm{e}_{2}$ is the sufficient and necessary condition of the truth of $<$ This speck is red at $\mathrm{t}>$. Therefore, the location, $\mathrm{e}_{1}$, and the individual property of redness, $\mathrm{e}_{2}$, are ontologically good justifiers for $<$ This speck is red $>$. In Example 1, the joint existence of Jones, a Ford, and the individual event of a Ford being driven by Jones, $\mathrm{e}_{3}$, is the sufficient and necessary condition of the truth of $<$ Jones drives a Ford at $\mathrm{t}>$. Therefore, Jones, a Ford (independent entities) and the individual event, $\mathrm{e}_{3}$, (trope) are the ontologically good justifiers of $<$ Jones drives a Ford $>$.

We claim that accepting our Assumption excludes accepting sense experiences in the role of ontologically good justifiers. The metaphysical status of sense experiences and ontologically good justifiers is different, although ontologically good justifiers are objects of mental acts, in particular, of the acts of perception. ${ }^{13}$ Thus, we have two different concepts of evidence:

(1) The evidence given by epistemically good justifiers, (EE) and

(2) The evidence given by the perception of ontologically good justifiers, $(\mathrm{OE})$.

Sense experiences, if they fulfill the condition of Definition 1, are epistemically good justifiers. The question arises if we really need the evidence given by the perception of ontologically good justifiers. Yes, we do. This kind of evidence may be properly called the ground of knowledge. We need this ground, since we need to formulate an adequate definition of propositional knowledge for natural language propositions modeled by our language L. We shall argue below that it may happen that sense experiences, being epistemically good justifiers, do not

\footnotetext{
${ }^{13}$ For a discussion of dependent entities as objects of acts of perception see MULLIGAN, SIMONS, SMITH [1984], pp. 304-308. Here is a passage from this discussion concerning the perception of individual events: "When we see Rupert's smile, we see something just as spatiotemporal as Rupert himself, and not something as absurd as a spatio-temporal entity that somehow contains a concept or a universal" (306). Cf. also SCHELLENBERG [2011].
} 
guarantee knowledge, and we must take into account ontologically good justifiers to explain why that may happen.

The traditional definition of knowledge formulates sufficient (if taken jointly) and necessary (if taken individually) conditions of knowledge in the following way. ${ }^{14}$

Definition 3 a knows $<\mathrm{P}>$ if and only if

- $\quad<\mathrm{P}>$ is true, and

- a believes $<\mathrm{P}>$, and

- $\quad \mathrm{a}$ is justified in believing $<\mathrm{P}>$.

Gettier in his (1963) paper convincingly argues that Definition 3 does not give us the sufficient condition of knowledge. Although the Reader may be familiar with Gettier's counterexamples, we must describe them to make our further discussion easier.

Case 1 Smith and Jones apply for a job in a company. The president of the company assured Smith that Jones would be chosen. Since it happened that Smith counted the coins in Jones's pocket a few minutes ago, Smith has strong evidence for the belief (B1):

(B1) <Jones will get the job, and Jones has 10 coins in his pocket>.

This proposition entails the formally correct conclusion (C1):

(C1) < The man who will get the job has ten coins in his pocked $>$.

Further facts are the following: Smith (not Jones) gets the job, and what is unknown to Smith, there are 10 coins in Smith's pocket. We get then:

(a) Smith's conclusion $\langle(\mathrm{C} 1)>$ is true;

(b) Smith believes $<(\mathrm{C} 1)>$;

(c) Smith is justified in believing $\langle(\mathrm{C} 1)\rangle$ by the closure principle for justification, that is, if Smith is justified in believing $\langle(\mathrm{B} 1)>$, and $\langle(\mathrm{B} 1)\rangle$ entails $\langle(\mathrm{C} 1)>$, then Smith is justified in believing $<(\mathrm{C} 1)>$, if he accepts $(\mathrm{C} 1)$ as a result of that entailment.

But it is not true in this scenario that Smith knows $<(\mathrm{C} 1)>$.

Case 2 Smith remembers that Jones always in the past owned a car, and always a Ford. Recently Jones offered Smith a ride while driving a Ford. Thus, Smith has strong evidence for believing (B2):

(B2) $<$ Jones owns a Ford $>$.

Smith has also a friend Brown, but he does not know where Brown is at present. Next, he formulates the formally correct conclusion (C2):

${ }^{14}$ Cf. GETTIER [1963]. 
(C2) <Either Jones owns a Ford, or Brown is in Barcelona $>$.

But facts are the following: Jones does not own a Ford, although he rented a Ford, and it happened - which is unknown to Smith - that Brown is in Barcelona. We get then:

(a) Smith's conclusion $\langle(\mathrm{C} 2)>$ is true;

(b) Smith believes $<$ (C2) $>$;

(c) Smith is justified in believing $\langle(\mathrm{C} 2)>$ by the closure principle for justification.

But it is not true in this scenario that Smith knows $<(\mathrm{C} 2)>$.

These two cases suggest that the traditional definition of knowledge does not offer the sufficient condition of truth for "a knows $<$ P $>$ ". We shall argue that in both cases Smith has epistemically good justifiers which do not guarantee knowledge. In Case 1, Smith thinks about Jones as the man who will get the job, while the truth is that Smith himself gets the job. Smith's conclusion $<(\mathrm{C} 1)>$ is entailed by the false premise $<(\mathrm{P} 1)>$ :

(P1) $<$ Jones will get the job $>$.

Smith has strong evidence to believe that the premise $<(\mathrm{P} 1)>$ is true, but his evidence being an epistemically good justifier has nothing to do with the ontologically good justifiers of $\langle(\mathrm{P} 1)>$, which could be recognized if $\langle(\mathrm{P} 1)>$ was true. In Case 2, Smith's true conclusion $\langle(\mathrm{C} 2)>$ is entailed by the false premise $<(\mathrm{P} 2)>$ :

(P2) $<$ Jones owns a Ford $>$.

Although Smith has strong evidence to believe that premise $<(\mathrm{P} 2)>$ is true, and his evidence is an epistemically good justifier, the ontologically good justifiers of $\langle$ (P2) $\rangle$, which could be recognized if $\langle(\mathrm{P} 2)\rangle$ was true, do not coincide with Smith's epistemically good justifier of $<(\mathrm{P} 2)>$.

Why are Smith's epistemically good justifiers of $\langle(\mathrm{C} 1)\rangle$ and $\langle(\mathrm{C} 2)>$ in both cases not ontologically good justifiers? The most straightforward answer would be the following. This is so, because Smith's conclusions $\langle(\mathrm{C} 1)\rangle$ and $\langle(\mathrm{C} 2)\rangle$ have truth conditions which do not coincide with Smith's respective epistemically good justifiers. In Case 1, the ontologically good justifiers are the existing non-mental entities whose joint existence is sufficient and necessary for the truth of $\left\langle(\mathrm{C} 1)>\right.$, that is, Smith himself as employee at $t^{\prime} \geq t$ and 10 coins in his pocket at $t$. In Case 2, the ontologically good justifiers are the entities whose joint existence is sufficient and necessary for the truth of $\langle(\mathrm{C} 2)\rangle$, that is, Brown, the location $=$ Barcelona, and the individual event of being Brown in Barcelona at $t$. In both cases the ontologically good justifiers do not coincide with the epistemically good justifiers: Smith's evidence that Jones will get the job, and Smith's evidence that Jones has 10 coins in his pocket (in Case 1), and Smith's 
evidence that Jones owns a Ford (in Case 2). One may have an epistemically good justifier in believing a false proposition. But in the case of false propositions there are no ontologically good justifiers. Thus, in such cases, no coincidence between epistemically and ontologically good justifiers is possible. Let us now consider Gettier's counterexamples in our framework.

Example 3. Smith's visual experience at $\mathrm{t}<\mathrm{Johns}$ has 10 coins in his pocket $>$ and Smith's testimony at $\mathrm{t}<$ Jones will get the job $>$ are epistemically good justifiers for $<$ The man who will get the job has 10 coins in his pocket $>$ if and only if Smith believes that $<$ The man who will get the job has 10 coins in his pocket at $\mathrm{t}>$ is true.

Example 4. The joint existence of the man who gets the job at t' $\geq \mathrm{t}$, and the existence of 10 coins in his pocket at $t$ is the sufficient and necessary condition of the truth $<$ The man who will get the job has 10 coins in his pocket at $\mathrm{t}>$. Thus, the man who gets the job at $t^{\prime} \geq t$ and 10 coins in his pocket at $t$ are jointly the ontologically good justifiers of $<$ The man who will get the job has 10 coins in his pocket>, that is, of $\langle(\mathrm{C} 1)>$.

Example 3 and Example 4 show that Smith's epistemically good justifier of $<$ Jones will get the job $>$ does not coincide with an ontologically good justifier of $<(\mathrm{C} 1)>$, because Jones $\neq$ the man who gets the job at $\mathrm{t}$ '.

Example 5. Smith's visual experience at $\mathrm{t}<$ Jones drives a Ford $>$ which is the epistemically good justifier of $<$ Jones drives a Ford $>$ coincides with the ontologically good justifiers of $<$ Jones drives a Ford $>$, that is, with the joint existence of Jones, a Ford and the individual event of a Ford being driven by Jones at $\mathrm{t}, \mathrm{e}_{3}$.

Example 6. The joint existence at $\mathrm{t}$ of Jones and a Ford, and the individual property of Jones's being the owner of a Ford, $\mathrm{e}_{4}$, is the sufficient and necessary condition of the truth of $<$ Jones owns a Ford $>$, and a sufficient condition of the truth of $<$ Either Jones owns a Ford or Brown is in Barcelona at $\mathrm{t}>$. Thus, Jones and $a$ Ford and the individual property of Jones's being the owner of a Ford at $t$ are jointly ontologically good justifiers of $<$ Either Jones owns a Ford or Brown is in Barcelona at $\mathrm{t}>$, that is, of $\langle(\mathrm{C} 2)>$. The individual property of Jones's being the owner of a Ford at $t$ is essentially dependent on the existence of Jones and a Ford at $t$.

Example 5 and Example 6 show that Smith's epistemically good justifier of $<$ Jones owns a Ford $>$, that is, his visual experience at $\mathrm{t}<$ Jones drives a Ford $>$, does not coincide with ontologically good justifiers of $<(\mathrm{C} 2)>$. 
In the light of the above discussion, we have reasons to give the following sufficient (if taken jointly) and necessary (if taken individually) conditions for the truth of any proposition of our language $\mathrm{L}$ which stands for the schema: "a knows $<$ P $>$ ".

Definition 4 a knows $<\mathrm{P}>$ in $\mathrm{L}$ if and only if

- $\quad<\mathrm{P}>$ is true in $\mathrm{L}$, and

- a believes $<\mathrm{P}>$, and

- a has epistemically good justifiers of $<\mathrm{P}>$, and

- a's epistemically good justifiers of $\langle\mathrm{P}>$ coincide with ontologically good justifiers of $<\mathrm{P}>$.

It is easy to notice that Smith in the Gettier counterexamples does not know $<(\mathrm{C} 1)>$ and does not know $<(\mathrm{C} 2)>$ if "a knows $<\mathrm{P}>$ " is defined by Definition 4 . As has been shown above, in both cases considered by Gettier, the condition of coincidence of epistemically good justifiers of $<\mathrm{P}>$ and ontologically good justifiers of $<\mathrm{P}>$ does not hold.

\section{A Solution}

We agree with the diagnosis of the Gettier Problem which points to the lack of successful coordination between the truth of $\langle\mathrm{P}>$ and the subject's justification of $<\mathrm{P}>$. The same opinion has been expressed by Floridi in his [2004] paper $^{15}$ :

A Gettier-type counterexample arises because the truth and the justification of $p$ happen to be not only independent (as they should be, since in this context we are dealing with fallibilist knowledge) but also opaquely unrelated, that is, they happen to fail to converge or to agree on the same propositional content $p$ in a relevant and significant way, without S realizing it (Gettierization) (FLORIDI [2004], p. 64).

Floridi makes use of the following assumptions concerning the Gettier Problem:

(*) the conception of knowledge occurring in the Gettier Problem is entirely fallibilist,

$(* *)$ the conception of knowledge occurring in the Gettier Problem is given by the traditional definition of knowledge (see Definition 3).

\footnotetext{
${ }^{15}$ The literature on the Gettier Problem is vast. I should like to mention only some of the earlier works such as GOLDMAN [1967], LEHRER, PAXSON [1969], DRETSKE [1971], NOZICK [1981], KIRKHAM [1984], SCHREIBER [1987], ZAGZEBSKI [1994], STEUP [2001a], STANLEY, WILLIAMSON [2001], FLORIDI [2004], and HETHERINGTON [2012].
} 
Therefore, Floridi's conclusion about the logical unsolvability of the Gettier Problem applies to the traditional fallibilist conception of knowledge, that is, such a conception of knowledge for which the lack of coordination between the truth of $\langle\mathrm{P}>$ and the subject's justification of $<\mathrm{P}>$ cannot be excluded. We agree with Floridi's conclusion that the fallibilist notion of empirical knowledge precludes a solution to the Gettier Problem.

Hetherington's diagnosis (in [2012]) of the Gettier Problem also appeals to the distinction: fallibilism vs. infallibilism. In his view, when we try to solve the Gettier Problem, we have "jointly unsatisfiable constraints", since we need to find a fallibilist analysis of knowledge, and retain a latent infallibilism of the standard interpretation of Gettier cases. Thus, Hetherington concludes:

To solve the standardly described Gettier problem in the standardly desired way is impossible (HETHERINGTON [2012], p. 228).

Fallibilism is generally understood as the view that we need not have logically conclusive justifications for what we know, that a justified true belief may be considered empirical knowledge even if we can rationally doubt it. Its opposition is infallibilism which is the view that knowledge is absolutely certain and it cannot be rationally doubted. The problem is that there are empirical justified true beliefs which are absolutely certain, that is, which satisfy the condition of infallibilism, as well as there being justified true beliefs which can be revised by further observations. We do not agree with Hetherington's conclusion quoted above. Our contention is that for indefinitely many instances of infallible empirical knowledge, the Gettier Problem has a solution. To make our discussion more perspicuous, let us define the fallibilist and infallibilist notions of knowledge.

Definition 5 The fallibilist notion of knowledge: a knows $<\mathrm{P}>$ in $\mathrm{L}$ if and only if

- $\quad<\mathrm{P}>$ is true, and

- $\quad \mathrm{a}$ is justified in believing $<\mathrm{P}>$ on the evidence $<\mathrm{c}>$, and

- $<\mathrm{P}>$ does not need to be entailed by $<\mathrm{c}>$.

Definition 6 The infallibilist conception of knowledge: a knows $<\mathrm{P}>$ in $\mathrm{L}$ if and only if

- $\quad<\mathrm{P}>$ is true, and

- $\quad \mathrm{a}$ is justified in believing $<\mathrm{P}>$ on the evidence $<\mathrm{c}>$, and

- $\quad<\mathrm{c}>$ entails $<\mathrm{P}>$.

Let us compare these definitions with Definition 4 which contains the additional condition of coincidence of epistemically good justifiers and ontologically good 
justifiers. This condition tells us that we should be careful looking for evidence as the ground of our knowledge. We should be also careful formulating the content of our sense experiences, and in each case we should ask the question if our epistemically good evidence (EE) is ontologically good evidence (OE), that is, if the joint existence of entities perceived in our sense experience is the sufficient and necessary condition of the truth of the atomic proposition which is epistemically justified by the respective sense experience. In other words, to get knowledge we should be able to consider our justification from the point of view of the attributor of knowledge. Smith's sense experience at $t<$ Jones drives a Ford $>$ is $(\mathrm{OE})$ for the proposition $<$ Jones drives a Ford $>$, since the joint existence of entities perceived at $t$ by Smith, that is, Jones, $\mathrm{e}_{5}$, a Ford, $\mathrm{e}_{6}$, and the individual event of a Ford being driven by Jones at $t, e_{3}$, is the sufficient and necessary condition of the truth of $<$ Jones drives a Ford at $t>$. Table 1 . below shows how we get knowledge from visual experience, if the condition of coincidence of epistemically good justifiers and ontologically good justifiers is satisfied.

Table 1. The illustration of Smith's knowledge $<$ Jones drives a Ford $>$

\begin{tabular}{|c|c|c|c|}
\hline EE & OE & EE $\rightarrow$ OE & EE $\Rightarrow$ OE \\
\hline $\begin{array}{c}<\mathrm{p}>:=\text { visual experience }= \\
<\text { Jones drives a Ford }>\end{array}$ & $\mathrm{e}_{3}, \mathrm{e}_{5}, \mathrm{e}_{6}$ & entailment & strict relevant entailment \\
\hline
\end{tabular}

Source: author coverage.

\section{FACT (1)}

The table illustrates the following logical relations ${ }^{16}$ :

(1) $\langle\mathrm{p}\rangle:=$ visual experience entails E! $\mathrm{e}_{3}$

(2) $\left\langle\mathrm{p}>:=\right.$ visual experience entails $E$ ! $\mathrm{e}_{5}$

(3) $\left\langle\right.$ p $>$ := visual experience entails E! $\mathrm{e}_{6}$

(4) $E$ ! $e_{3} \wedge E$ ! $e_{5} \wedge E$ ! $e_{6}$ strictly and relevantly entails the proposition $<$ Jones drives a Ford at $\mathrm{t}>$.

The joint existence of the individual event of driving a Ford by Jones at $t$, Jones and a Ford necessitates the proposition $<$ Jones drives a Ford at $\mathrm{t}>$, which is true at every time in every place, and for everyone. ${ }^{17}$ Thus, it is an instance of infallible knowledge. Smith's visual experience at $\mathrm{t}<$ Jones drives a Ford $>$ entails the ontologically good justifiers of $<$ Jones drives a Ford $>$ whose joint

\footnotetext{
16 "entails" means "validly deduced". The logical form of visual experience content is regarded as closest to that as introduced by Davidson. See DAVIDSON [1967] and [2001].

${ }^{17}$ Understood in that way, $<$ Jones drives a Ford at $\mathrm{t}>$ is an absolute truth. For fuller analysis of the notion of absolute truth, see SIMONS [2003]. The concept of necessitation is discussed in CAMERON [2008]. Cf. also FORREST, KHLENTZOS [2000], and ARMSTRONG [2004].
} 
existence necessitates the proposition $<$ Jones drives a Ford at $\mathrm{t}>$. Therefore, Smith knows $<$ Jones drives a Ford $>$, and the proposition is an instance of infallible knowledge. This notion of knowledge excludes the case when the subject has an act of sense experience in normal conditions which entails OE, while the proposition $\langle\mathrm{p}>$ is false. The logical consequence relation of strict relevant entailment excludes as illegitimate such a conclusion which ignores any conjunct of the premise. This explication leads to our ultimate definition of "a knows $<\mathrm{P}>$ " in $\mathrm{L}$.

Definition 7 a knows $<\mathrm{P}>$ in $\mathrm{L}$ if and only if

- $\quad<\mathrm{P}>$ is true in $\mathrm{L}$, and

- a believes $<\mathrm{P}>$, and

- a has epistemically good evidence for $<\mathrm{P}>$

- a's epistemically good evidence for $<\mathrm{P}>$ entails ontologically good evidence for $<\mathrm{P}>$ which necessitates the truth of $<\mathrm{P}>$.

Suppose that Smith's epistemically good evidence is his visual experience at $t$ $<$ This cube is red $>$ in the room with a red light-bulb. Suppose that the proposition $<$ This cube is red at $\mathrm{t}>$ is true. Then its being true entails the joint existence of this cube, as an independent object, and the trope of redness. Although this cube is a part of the ontologically good evidence for $<$ This cube is red $>$, that is, a part of the joint existence of this cube and the trope of redness, as well as this cube being a part of the ontologically good evidence for $<$ This cube is white at $\mathrm{t}>$, the whole: ontologically good evidence for $\langle$ This cube is red at $t>$ does not exist, because the proposition $<$ This cube is red at $t>$ is false. Therefore there is no the whole: ontologically good evidence for $<$ This cube is red at $t>$, because the conclusion asserting the existence of the individual property of redness of this cube is false, and according to our Definition 7, Smith does not know $<$ This cube is red $>$. If Smith's epistemically good evidence at $t$ is $<$ This cube looks red $>$, then his evidence entails the existence of this cube and the existence of the individual event of Smith looking at the cube in the room with the red light. The joint existence of these entities is the ontologically good evidence for $<$ This cube looks red at $t>$, which strictly and relevantly entails $<$ This cube looks red $>$, and according to our Definition 7 Smith knows $<$ This cube looks red $>$. Suppose now that this cube is red, and Smith's epistemically good evidence for $<$ This cube is red $>$ is his visual experience at $t<$ This cube is red $>$ in the room with a red light-bulb, and that Smith is unaware of the fact he is looking at the cube in this light. His epistemically good evidence entails the existence of this cube and the individual property of redness of this cube, and the joint existence of these two entities is the ontological good evidence of the proposition $<$ This cube is red at $t>$, therefore according to Definition 7 , Smith 
knows $<$ This cube is red $>$. Even that case allows for knowledge-attribution without contradicting our intuitions.

Our definition cannot be regarded as an effective criterion of knowledge. It may happen that the subject does not formulate the content of visual experience with full awareness. In such cases, our definition will not help to decide whether the subject knows or does not. In this respect, our definition shares the lack of an effective criterion of defined concept with many standard definitions of formal semantics. Note that Gettier's counterexamples are formulated from the point of view of the attributor of knowledge, and from this perspective our Definition 7 has been formulated.

Barn County Example. Let us consider the familiar Barn County case. Suppose that the landscape close to a road leading through Barn County has barn-facades which from the road look exactly like barns. If Henry is driving along the road he has each time a false belief in the presence of a "barn", although justified by his visual experience. Finally, when driving along this road, it happens that he looks at the one and only real barn in Barn County, so this time his belief that this is a barn is justified and true. But in this scenario, Henry's true and justified belief $<$ This is a barn $>$ is not an instance of knowledge. How could we explain the lack of knowledge in that case?

Each time in the presence of a barn façade Henry has epistemically good evidence given by his act of perception, that is, by his non-veridical visual experience directed at $<$ This is a barn $>$ for $<$ This is a barn facade $>$. However, in each case of a barn façade, his epistemically good evidence does not entail ontologically good evidence, that is, the existence of the barn façade on such and such a location and at such and such a time. In consequence, his visual experience $<$ This is a barn $>$, although it entails $E$ ! $e_{7}\left(e_{7}:=\right.$ this barn), cannot be regarded as ontologically good evidence for <This is a barn façade $>$, and according to Definition 7, Henry does not know $<$ This is a barn façade $>$. But if it is so, Henry, in the Barn County scenario, cannot make the distinction between his epistemically good evidence which entails the ontologically good evidence on the one hand, and his epistemically good evidence which does not entail the ontologically good evidence, on the other. In consequence, he cannot have knowledge of $<$ This is a barn façade $>$. The lack of this instance of knowledge implies, on the basis of the Barn County scenario, that Henry also does not know $<$ This is a barn $>$. If we apply our Definition 7 to this case, we get the same conclusion. What is the ontologically good evidence for $<$ This is a barn $>$ in the Barn County scenario? It is the joint existence of this barn and its trope of real existence in space and time, very roughly speaking. What is the trope of the real existence of this barn? The phrase the trope of the real existence denotes 
a bundle of tropes connected with the perceptible features of this barn as well with its utility functions. Although Henry's epistemically good experience entails the existence of this barn, it does not entail many tropes belonging to that bundle of tropes, and, in consequence, Henry's epistemically good evidence $<$ This is a barn $>$ does not entail the joint existence of this barn with its bundle of tropes. We do not claim that Henry is not able to notice a difference between a real barn and a barn façade in general. We assume silently that he is able to make such a distinction. But in the scenario of the Barn County case, he is not aware of this distinction, and we suppose that Henry making it is impossible. Therefore, Definition 7 attributes knowledge to subjects in conformity with our intuitions if the subjects of beliefs satisfy the Presupposition accepted above. The Barn County case is illustrated by Table 2. and Table 3. below.

Table 2. The illustration of the lack of Henry's knowledge $<$ This is a barn façade $>$

\begin{tabular}{|c|c|c|c|}
\hline EE & $\mathrm{OE}$ & $\mathrm{EE} \rightarrow \mathrm{OE}$ & $\mathrm{EE} \Rightarrow \mathrm{OE}$ \\
\hline sual experience: $=<$ This is a barn $>$ & $\mathrm{e}_{7}:=$ this barn facade & ---------------- & \\
\hline
\end{tabular}

Source: author coverage.

FACT (2)

- <This is a barn> does not entail the existence of this barn façade.

Table 3. The illustration of the lack of Henry's knowledge $<$ This is a barn $>$

\begin{tabular}{|l|l|c|c|}
\hline \multicolumn{1}{|c|}{$\mathrm{EE}$} & $\mathrm{OE}$ & $\mathrm{EE} \rightarrow \mathrm{OE}$ & $\mathrm{EE} \Rightarrow \mathrm{OE}$ \\
\hline $\begin{array}{l}\text { visual experience:= } \\
\text { KThis is a barn }>\end{array}$ & $\begin{array}{l}\text { The joint existence } \\
\text { of this barn and its } \\
\text { bundle of tropes }\end{array}$ & & \\
\hline
\end{tabular}

Source: author coverage.

\section{FACT (3)}

- $<$ This is a barn> does not entail the joint existence of this barn and its bundle of tropes.

Whether the epistemically good evidence entails the existence of the respective ontologically good justifier(s), or not depends on context. Imagine that there are no barn-facades in Barn County at all, but the only the real barn which Henry perceives from the road. Suppose that Henry's visual experience is <This is a barn façade $>$. Do we say that Henry knows $<$ This is a barn $>$ in this case? Of course, not. We say that according to Definition 7, his epistemically good evidence does not entail the ontologically good evidence for $<$ This is a barn $>$. The analysis of different scenarios suggests that knowledge-attribution is highly context sensitive. 


\section{Conclusions}

We have made use of the conception of substantial truth to explicate the Gettier Problem. Our definition of knowledge avoids the Gettier Problem. It defines empirical infallibilist propositional knowledge for the given language L which models simple resources of natural language, and which may serve to a certain degree as the ground for more complicated semantic constructions. The application of our definition of knowledge to the entire natural language, or to the entire language of an empirical science may encounter obstacles connected with divergent syntactic forms of natural language propositions and its semantic indeterminacy, the generality of scientific hypotheses, as well as with advanced methods of observation. But our definition applies well to less advanced parts of those languages. The truth and knowledge of scientific hypotheses have their own problems which should be left for another occasion. Concluding, we have reasons to claim that although our sources of knowledge are in principle fallible, we are neither compelled to accept fallibilism concerning knowledge, nor skepticism in its Kirkham version as well as in its Pyrrhonian version, meant as the attitude which refrains from opining about whether we can have knowledge. $^{18}$

\section{ACKNOWLEDGEMENTS}

I should like to thank my No. 1 Referee for Synthese for reading an earlier version of this paper with full understanding, and for commenting on it in a way which turned out to be especially beneficial for its final version .

\section{References}

ARMSTRONG, D. M. [2004], Truth and Truthmakers. Cambridge: Cambridge University Press.

BACON, J. [1995], Universals and Property Instances. The Alphabet of Being. Aristotelian Society Series 15. Oxford: Blackwell.

BERGMAN, M. [2004], "Epistemic Circularity: Malignant and Benign", Philosophy and Phenomenological Research, 69, 709-727.

CAMERON, R. P. [2008], “Truthmakers and Necessary Connections”, Synthese 161, 27-45.

CAMPBELL, K. [1990], Abstract Particulars. Oxford: Blackwell.

\footnotetext{
18 The term "Pyrrhonian skepticism" has been borrowed by me from P. Klein who compares Pyrrhonian skepticism with Academic skepticism which is the view that we cannot have knowledge of a certain set of propositions. See Klein (2002).
} 
DAVIDSON, D. [1967], "The Logical Form of Action Sentences", [in:] Rescher, N. (ed.) The Logic of Decision and Action. Reprinted in Davidson 2001.

DAVIDSON, D. [1983], "A Coherence Theory of Truth and Knowledge”, in his The Essential Davidson. Oxford: Clarendon Press 2006.

DAVIDSON, D. [2001], Essays on Actions and Events. Oxford: Clarendon Press. $2^{\text {nd }}$ edn.

DRETSKE, F. [1971], “Conclusive Reasons”, Australiasian Journal of Philosophy 49, 1-22.

FENNELL, D., CARTWRIGHT, N. [2010], "Does Roush Show that Evidence Should Be Probable?", Synthese 175, 289-310.

FLORIDI, L. [2004], “On the Logical Unsolvability of the Gettier Problem”, Synthese, 142, 61-79.

FORREST, P., KHLENTZOS D. (eds) [2000], "Truth Maker and Its Variants", Special Issue of Logique et Analyse 43, No. 169-170.

GETTIER, E. L. [1963], “Is Justified True Belief Knowledge?”, Analysis 23: 121-123.

GOLDMAN, A. [1967], “A Causal Theory of Knowing”, The Journal of Philosophy 64, 357-372.

HEIL, J. [2003]. From an Ontological Point of View. Oxford: Clarendon Press.

HETHERINGTON, S. [2012], "The Gettier-Illusion: Gettier Partialism and Infallibilism", Synthese 188, 217-230.

KIRKHAM, R. [1984], “Does the Gettier Problem Rest on a Mistake?” Mind 93, 501-513.

KLEIN, P. [2002], „Skepticism”, [in:] Moser, P. (ed.) The Oxford Handbook of Epistemology, Chapter 11.

LEHRER, K., PAXSON, T. [1969], "Knowledge: Undefeated Justified True Belief”, The Journal of Philosophy 66, 1-22.

MAURIN, A.-S. [2002], If Tropes. Dordrecht: Kluwer.

MAURIN, A.-S. [2010], “Trope Theory and the Bradley Regress”, Synthese 175, 311-326.

MCDANIEL, K. [2001], "Tropes and Ordinary Physical Objects", Philosophical Studies 104, 269-290.

MOSER, P. (ed.) [2002], The Oxford Handbook of Epistemology. Oxford: Oxford University Press.

MULligAN, K., SIMONS, P., SMITH, B. [1984], "Truth - Makers", Philosophy and Phenomenological Research, 44, 287-321.

NOZICK, R. [1981], Philosophical Explanations. Cambridge, MA: Harvard University Press.

ROUSH, S. [2005], Tracking Truth: Knowledge, Evidence and Science. Oxford: Clarendon Press.

SCHELLENBERG, S. [2011], "Ontological Minimalism about Phenomenology", Philosophy and Phenomenological Research 83, 1-40.

SCHREIBER, D. S. G. [1987], "The Illegitimacy of Gettier Examples”, Metaphilosophy 18, 49-54.

SELLARS, W. [1956], "Empiricism and the Philosophy of Mind", [in:] Feigl, H. and Scriven, M. (eds), Minnesota Studies in the Philosophy of Science, vol. I. Minneapolis, MN: University of Minnesota Press, pp. 253-329. Reprinted [in:] Sellars, W. [1963], Science, Perception and Reality, London: Routledge \& Kegan Ltd. 
SIMONS, P. [1994], "Particulars in Particular Clothing: Three Trope Theories of Substance", Philosophy and Phenomenological Research 54, 553-575.

SIMONS, P. [2000], "Identity through Time and Trope Bundles”, Topoi 19, 147-155.

SIMONS, P. [2003], "Absolute Truth in a Changing World", [in:] Hintikka, J. et al. (eds), Philosophy and Logic in Search of the Polish Tradition, Dordrecht: Kluwer Academic Publishers.

STANLEY, J., WILLIAMSON, T. [2001], "Knowing - How”. The Journal of Philosophy 98, 411-444.

STEUP, M. [2001a], „The Analysis of Knowledge”, in: Stanford Encyclopedia of Philosophy. $\mathrm{http} / / /$ plato.stanford.edu/entries/knowledge-analysis/.

STEUP, M. [2001b], „Foundationalism, Sense-Experiential Content, and Sellar's Dilemma”, Manuscript: http://web.stcloudstate.edu/msteup/SellDilem.html.

TRETTIN, K. [2001], „Ontologische Abhängigkeit in der Tropentheorie“, Metaphysica. International Journal for Ontology and Metaphysics 2, 23-54.

WILLIAMSON, T. [2000], Knowledge and Its Limits. Oxford: Oxford University Press.

ZAGZEBSKI, L. T. [1994], “The Inescapability of Gettier Problems”, Philosophical Quarterly 44, $65-73$. 